\title{
COMPETITIVIDADE DA CADEIA PRODUTIVA DA MADEIRA DE EUCALIPTO NO BRASIL ${ }^{1}$
}

\author{
Naisy Silva Soares², Márcio Lopes da Silva ${ }^{3}$, José Luiz Pereira de Rezende ${ }^{4}$ e Marília Fernandes \\ Maciel Gomes ${ }^{3}$
}

\begin{abstract}
RESUMO - Este trabalho teve como objetivo geral analisar a competitividade da cadeia produtiva da madeira de eucalipto no Brasil, comparando diferentes sistemas de produção, por meio da matriz de análise política (MAP). Pelos resultados, conclui-se que a lucratividade privada e social da produção e comercialização da madeira de eucalipto foi positiva e maior em áreas motomecanizáveis; os produtores brasileiros foram penalizados por políticas públicas adotadas para o setor; a produção em áreas motomecanizáveis apresentou-se mais competitiva e menos exposta aos efeitos negativos das políticas públicas; e os produtores nacionais tiveram seus lucros reduzidos.
\end{abstract}

Palavras-chave: Matriz de análise política, Madeira de eucalipto e Política florestal.

\section{COMPETITIVENESS OF THE BRAZILIAN EUCALYPTUS PRODUCTION CHAIN}

\begin{abstract}
The present work aimed to analyze the competitiveness of the eucalyptus productive chain in Brazil, comparing different production systems, through a policy analysis matrix (PAM). Based on the results obtained, it was concluded that the private and social profitability of the production and commercialization of eucalyptus was positive and greater in flat areas; Brazilian producers were penalized by the public policies adopted for the sector; the production in flat areas was more competitive and less exposed to the negative effects of public policies; and national producers had decreased profits.
\end{abstract}

Keywords: Policy analysis matrix, Eucalyptus wood e Forestry policies.

\section{INTRODUÇÃO}

O eucalipto é um gênero arbóreo nativo da Austrália, com mais de 600 espécies conhecidas. A introdução do eucalipto em bases técnicas no Brasil iniciou-se em 1904, no Horto de Jundiaí, SP, conduzida por Edmundo Navarro de Andrade. Entretanto, há informações da existência de dois exemplares de E. gigantea no Jardim Botânico do Rio de Janeiro, em 1825, e de alguns exemplares no Rio Grande do Sul, em 1865(ASSOCIAÇÃOMINEIRA DE SILVICULTURA - AMS, 2008).

Em 2008, existia no Brasil 4.258.704 ha de florestas plantadas com eucalipto. Minas Gerais é o Estado com maior percentual de área plantada (29\%), seguido por
São Paulo (22\%), Bahia (14\%), Rio Grande do Sul (7\%), Mato Grosso do Sul (6\%) e Espírito Santo (5\%); os demais estados responderam por 17\% (ASSOCIAÇÃO BRASILEIRA DOS PRODUTORES DE FLORESTAS PLANTADAS - ABRAF, 2009).

Em 2006, a produtividade média das florestas nacionais de eucalipto alcançou $40 \mathrm{~m}^{3} / \mathrm{ha} / \mathrm{ano}$, enquanto no Uruguai, Indonésia, Chile, Estados Unidos, Canadá, Espanha e Finlândia, o que correspondeu a 25, 20, 25, 10, 7, 10 e 4 m³/ha/ano, respectivamente. Acrescenta-se, ainda, que no Brasil a rotação das florestas de eucalipto é de 7 anos, inferior a de países como África do Sul (8 - 10 anos), Chile (10 -12 anos), Portugal (12 - 15 anos), Espanha (12 - 15 anos) (BRACELPA, 2007).

\footnotetext{
${ }^{1}$ Recebido em 22.09.2008 e aceito para publicação em 02.03.2010.

${ }^{2}$ Universidade Estadual de Santa Cruz, Brasil. E-mail: < naisysilva@yahoo.com.br>.

${ }^{3}$ Universidade Federal de Viçosa, UFV, Brasil. E-mail: <marlosil@ufv.br>e <mfmgomes@ufv.br>.

${ }^{4}$ Universidade Federal de Lavras, UFLA, Brasil. E-mail: <jlprezen@ufla.br>.
} 
No que se refere aos custos totais de produção da celulose de fibra curta, em 2005 este foi de aproximadamente US\$ 450/tonelada no Brasil. Nos países de tradição florestal como Indonésia, Costa Leste do Canadá, Suécia, Finlândia, Portugal e Espanha, o custo total de produção de uma tonelada de celulose de fibra curta foi cerca de US\$ 400, US\$ 500, US\$ 550, US\$ 500, US\$ 500 e US\$ 550, respectivamente (MONTEBELLO, 2006).

O gênero pode ser usado na produção de óleos essenciais; produtos apícolas, celulose e papel, madeira serrada, postes e moirões, laminados, MDF, HDF, chapa de fibra, compensados, carvão e lenha (ASSOCIAÇÃO MINEIRA DE SILVICULTURA-AMS, 2009). Porém, em 2005, por exemplo, o consumo da madeira de eucalipto no Brasil concentrou-se, principalmente, na produção de celulose e na siderurgia a carvão vegetal, segmentos que consumiram entre 65\% e 75\% do total (ASSOCIAÇÃO MINEIRADE SILVICULTURA-SILVIMINAS, 2008).

Devido ao aumento da produção do setor florestal brasileiro, o consumo da madeira de eucalipto pelas empresas nacionais cresceu. No período de 1980 a 2005, por exemplo, o aumento no consumo dessa matériaprima pelas empresas de celulose do país foi, em média, de 5,8\% ao ano (SOARES, 2006), e a expectativa é de que esse consumo continue crescente nos próximos anos, pois está previsto para 2010 uma produção de 10.010 milhões de toneladas de celulose de fibra curta no país (BRACELPA, 2007). Já Gomes (2006) verificou que o consumo dessa matéria-prima nas empresas de ferro-gusa de Minas Gerais cresceu, aproximadamente, 22\%, no período de 2001 a 2005.

Os segmentos do setor florestal brasileiro, como celulose e papel, madeira serrada, compensado, aglomerado etc., ocupam posição de destaque no ranking dos maiores produtores e exportadores mundiais (FAO, 2008). Essa situação pode permanecer no futuro, e, além disso, o Brasil pode conquistar novos mercados e, com isso, contribuir ainda mais para o desenvolvimento socioeconômico do país, pois as empresas brasileiras são competitivas devido à alta produtividade dos reflorestamentos, em razão das condições climáticas favoráveis à atividade florestal no país, possibilitando ciclos de crescimento rápido e de alta qualidade, bem como ao baixo custo de produção em relação aos outros países. No mais, tem-se a aceitabilidade dos produtos brasileiros no mercado internacional, devido à sua alta qualidade (MEDEIROS e FONTES, 1994; PIZZOL e BACHA, 1998; VALVERDE et al., 2006; NOCE et al., 2003; COELHO e BERGER, 2004; NOCE et al., 2007; NOCE et al., 2008). Entretanto, o setor florestal brasileiro enfrenta a concorrência internacional e a falta de políticas adequadas para o seu desenvolvimento. E, como a madeira de eucalipto é insumo de grande importância, estudos mostrando os efeitos das políticas públicas na cadeia produtiva do eucalipto tornam-se relevantes, pois permitem identificar pontos de estrangulamento na estrutura de custos do setor produtivo dessa cadeia para que se possam direcionar políticas que objetivem a manutenção e, ou, a ampliação da capacidade produtiva e de exportação da celulose e dos outros produtos que utilizam a madeira de eucalipto no Brasil.

Nesse contexto, este trabalho teve como objetivo geral analisar a competitividade da cadeia produtiva da madeira de eucalipto no Brasil, comparando sistemas de produção com níveis tecnológicos diferenciados. Especificamente, pretendeu-se determinar a lucratividade privada e social na produção da madeira de eucalipto no Brasil para diferentes sistemas tecnológicos; identificar os efeitos de políticas públicas sobre os diferentes sistemas adotados, em relação ao mercado externo; e mensurar os indicadores que avaliam o grau de competitividade do setor produtivo, assim como a eficiência econômica e os efeitos das políticas nesse setor, levando em consideração os resultados privados e sociais.

\section{MATERIAL E MÉTODO}

\subsection{Referencial Teórico}

Este trabalho teve como referência a abordagem que relaciona a competitividade aos custos.

Segundo Rosado (1997), o conhecimento dos componentes dos custos é útil para compreensão da competitividade. Para essa autora, a competitividade resulta da interação entre os custos de produção e todos os custos adicionais incorridos para colocar a mercadoria para o comprador estrangeiro. Nesse sentido, para determinar a competitividade é necessário considerar os fatores e os efeitos de políticas que influenciam os preços enfrentados pelos agentes econômicos. Esses determinantes incluem eficiência produtiva, política de preços dos insumos, taxa de juros, taxa de câmbio e política de impostos e subsídios. 
O conceito de eficiência associa a competitividade de uma economia às condições gerais do processo de produção. Nesse sentido, o progresso tecnológico é um elemento central na configuração e evolução dos sistemas econômicos e dos fluxos internacionais de comércio, assim como o melhor aproveitamento de economias de escala, maior capacitação de mão de obra etc. (HAGUENAUER, 1989; ALVES, 2002). Os indicadores de eficiência relacionam-se com a comparação dos preços e custos unitários de um país com os de um determinado conjunto de competidores internacionais (IE/UNICAMP et al., 1993).

Os insumos comercializados internacionalmente estão sujeitos a impostos, tarifas ou subsídios que podem provocar distorções sobre a competitividade (FERREIRA NETO, 2005).

Assim, a competitividade é influenciada por uma grande quantidade de fatores inter-relacionados como tecnologia disponível e a forma como esta é aplicada, preços domésticos dos insumos produtivos, taxa de câmbio, taxa de paridade entre os parceiros comerciais do país, custos de transporte, estrutura de incentivos, barreiras tarifárias e não tarifárias no país importador, qualidade e imagem do produto etc. (BNDES, 1991 citado por FERREIRA NETO, 2005).

\subsection{Referencial Analítico}

O instrumental utilizado para atingir os objetivos deste trabalho foi o da matriz de análise política (MAP) de Monke e Pearson (1989). Com a MAP, podem-se identificar incentivos ou desincentivos para agentes econômicos; analisar o impacto de políticas diretas em nível de cadeia; verificar os efeitos de políticas sobre a lucratividade privada; e examinar os impactos favoráveis ou desfavoráveis à sociedade relativos a atividades econômicas (ALVES, 2002). Por isso, esse método é muito usado na análise da cadeia produtiva de produtos agropecuários (NELSON, 1991; NELSON e PANGGABEAN, 1991; ROSADO, 1997; AHMAD e MARTINI, 2000; MARRA, 2001; MARTINS, 2001; ALVES, 2002; MOHANTY et al., 2002; FERREIRANETO, 2005; MOSS, 2006; ROSADO et al., 2006).

No Brasil e na área florestal apenas no estudo de Rosado et al. (2006), a MAP foi utilizada para analisar a competitividade e os efeitos das políticas públicas sobre a produção da borracha natural nos Estados de São Paulo e Mato Grosso. Esses autores constataram que a produção da borracha natural naqueles Estados está sendo prejudicada com as políticas públicas, mas, apesar disso, é lucrativa e competitiva.

No exterior, pode-se citar o estudo de Maryani e Irawanti (1997), Hadi e Budhi (1997) e Endom (1999), utilizando a MAP na área florestal.

Maryani e Irawanti (1997) analisaram os impactos das políticas públicas na competitividade da produção de óleo de palma e da madeira industrial processada em Sumatra, Indonésia, mais precisamente na província de Riau, em 1997, que é composta por seis distritos. São eles: Pakan Baru, Kampar, Bengkalis, Inderagiri Hulu, Kepulauan Riau e Batam. Os referidos autores concluíram que tanto a produção de óleo de palma quanto a produção de madeira industrial processada são economicamente eficientes devido às políticas governamentais para essas mercadorias.

Hadi e Budhi (1997) estudaram a eficiência econômica e a vantagem comparativa dos pequenos produtores de borracha natural de Sumatra, Indonésia, em 1997, considerando o sistema agroflorestal e a monocultura. Esses autores constataram que os dois sistemas de produção não foram competitivos e que no sistema agroflorestal as perdas são maiores que no sistema de monocultura para os pequenos produtores.

Já Endom (1999) verificou os impactos das políticas públicas na competitividade da indústria de madeira na província de Jambi, Distrito de Bungo Tebo em Kabupaten, Indonésia, em 1997. As regiões que compuseram a amostra foram: PT Rimba Karya Indah, PT Dalek Esa Hutani, PT Gaya Wahana Timber e PT Sylvagama. Os resultados revelaram que a indústria da madeira na Indonésia que opera em larga escala é relativamente competitiva e possui elevada eficiência. Porém, as políticas públicas contribuíram para que o preço da tora no mercado doméstico ficasse menor que o preço mundial.

\subsection{Operacionalização do Modelo}

A MAP expressa a lucratividade definida como a diferença entre receitas e custos e mensura o efeito das divergências (políticas “distorcivas” e falhas de mercado), sendo a diferença entre os valores privados e valores sociais. A MAP é composta por duas colunas de custos, uma para insumos comercializáveis (tradeable) e outra para fatores domésticos (nontradeable). Os insumos intermediários-fertilizantes, 
Tabela 1 - Matriz de análise política (MAP).

Table 1 - Policy analysis matrix (PAM).

\begin{tabular}{lccc}
\hline Itens & Receitas & & Custos \\
\cline { 3 - 4 } & & Lucros & $\begin{array}{c}\text { Fatores } \\
\text { Domésticos }\end{array}$ \\
\hline Preços Privados & A & B & C \\
Preços Sociais & E & F & D \\
Efeitos de divergências & I & J & K \\
e eficiência política & & L \\
\hline
\end{tabular}

Fonte: MONKE e PEARSON, 1989.

Source: Monk and PEARSON, 1989

pesticidas, sementes, rações, eletricidade, transporte e combustível - são divididos, em seus componentes de insumos comercializáveis e não comercializáveis (Tabela1) (ALVES, 2002).

A manipulação dos valores contidos na MAP dão origem aos indicadores a seguir.

a) Lucro Privado (D): O D expressa o lucro obtido a preços de mercado, ou a preços privados (equação 1). Como valores praticados no mercado, esses sofrem interferências dos governos, na forma de tributos ou subsídios.

$$
D=A-B-C
$$

em que $\mathrm{A}=\mathrm{p}^{\mathrm{d}} \mathrm{q}^{\mathrm{d}} ; \mathrm{B}=\sum_{i=1}^{\mathrm{n}} \mathrm{p}_{\mathrm{i}}^{\mathrm{d}} \mathrm{q}_{\mathrm{i}}^{\mathrm{d}} ; \mathrm{C}=\sum_{\mathrm{j}=1}^{\mathrm{n}} \mathrm{w}_{\mathrm{j}}^{\mathrm{d}} \mathrm{l}_{\mathrm{j}}^{\mathrm{d}} ; \mathrm{A}=$ receita privada; $\mathrm{B}=$ custo dos insumos comercializáveis externamente; $\mathrm{C}=0$ custo dos insumos domésticos; $\mathrm{p}^{\mathrm{d}}=$ preço privado do produto; $\mathrm{q}^{\mathrm{d}}=$ quantidade total privada de determinado produto; $\mathrm{p}^{\mathrm{d}}=$ preço privado do insumo $\mathrm{i} ; \mathrm{q}_{\mathrm{i}}^{\mathrm{d}}=$ quantidade privada do insumo i utilizado na produção do bem considerado; $\mathrm{w}_{\mathrm{j}}{ }^{\mathrm{d}}=$ preço privado do insumo $\mathrm{j}$; e $1_{\mathrm{j}}^{\mathrm{d}}=$ quantidade privada do insumo $\mathrm{j}$ utilizado.

O cálculo da lucratividade privada mostra a competitividade da cadeia produtiva. Se os lucros privados forem negativos ( $\mathrm{D}<0$ ), os operadores estarão ganhando uma taxa de retorno subnormal. No entanto, se os lucros privados forem positivos ( $D>0$ ), os operadores estarão ganhando uma taxa de retorno sobrenormal, indicando que pode ocorrer expansão do sistema de produção em análise no futuro. O lucro normal ocorre se D = 0 (ROSADO et al., 2006).

b) Lucro Social $(\mathrm{H})$ : O H expressa o lucro alcançado a preços de sociais (equação 2).

$$
H=E-F-G
$$

em que $\mathrm{E}=\mathrm{p}^{\mathrm{s}} \mathrm{q}^{\mathrm{s}} ; \mathrm{F}=\sum_{i=1}^{\mathrm{n}} \mathrm{p}_{\mathrm{i}}^{\mathrm{s}} \mathrm{q}_{\mathrm{i}}^{\mathrm{s}} ; \mathrm{G}=\sum_{j=1} \mathrm{w}_{\mathrm{j}}^{\mathrm{s}} \mathrm{l}_{\mathrm{j}}^{\mathrm{s}} ; \mathrm{E}$ = receita social; $\mathrm{F}=$ custo dos insumo comercializáveis; $\mathrm{G}=$ custo dos insumos domésticos; $\mathrm{p}^{\mathrm{s}}=$ preço social do produto; $\mathrm{q}^{\mathrm{s}}=$ quantidade total do produto; $\mathrm{p}_{\mathrm{i}}^{\mathrm{s}}=$ preço social do insumo $\mathrm{i} ; \mathrm{q}^{\mathrm{s}}=$ quantidade do insumo i utilizado; $\mathrm{w}^{\mathrm{s}}$ = preço social do insumo $\mathrm{j}$; $\mathrm{e} 1_{\mathrm{j}}^{\mathrm{s}}=$ quantidade do insumo j utilizado.

Esses valores não sofrem interferências de governos. Assim, são considerados valores sociais ou econômicos e medem a eficiência do sistema de produção. Como medida de eficiência ou vantagem comparativa, o lucro social, quando negativo, indica que o sistema não é considerado economicamente viável no contexto de mercado internacional, sem assistência do governo. Tem-se uma indicação de que tal sistema não assegura a alocação economicamente eficiente de recursos escassos, dado que produz a custos sociais superiores aos custos de importação (ALVES, 2002; VIEIRA et al., 2001).

c) Efeitos das divergências e da eficiência política: Aqui são analisadas as diferenças entre as avaliações privadas e sociais de receitas, custos e lucros que devem ser explicadas pelos efeitos da distorção política ou pelas imperfeições nos mercados de produtos e fatores.

Os efeitos das divergências e da eficiência política podem ser verificados pelas transferência de receitas $(I=A-E)$, transferência de insumos $(J=B-F)$, transferência de fatores $(K=C-G)$ e transferência líquida $(L=D-H$ ou $L=I-J-K)$.

As transferências de receitas estão associadas à produção e as transferências de insumos, aos custos de insumos comercializáveis, que resultam de políticas que causam divergências entre os preços domésticos dos produtos e os preços internacionais, como políticas específicas de produtos (taxas ou subsídios) e política 
cambial. Por fim, as falhas de mercado podem também influenciar os preços dos produtos e de fatores. As transferências líquidas combinam efeitos de políticas "distorcivas" com aqueles de falhas de mercado de fator e políticas eficientes para compensá-los (ALVES, 2002).

A comparação entre sistemas de produção que geram bens idênticos foi feita pelos indicadores a seguir (ROSADO et al., 2006; MOSS, 2006; FERREIRA NETO, 2005):

a) Razão do Custo Privado (RCP): A RCP mostra quanto o sistema pode pagar pelos fatores domésticos, permanecendo competitivo, ou seja, equilibrando a receita com a despesa (sem lucro nem perda) após alcançar lucros normais. Para que o produtor alcance esse objetivo é necessário que os custos de seus fatores domésticos sejam menores que seus valores adicionais (diferença entre receita e custos dos insumos comercializáveis), a preços privados. Desse modo, para a maximização dos lucros é indispensável a minimização dessa razão, por meio do controle dos custos dos fatores domésticos (MOSS, 2006).

Essa razão é calculada como apresentado na equação 7 .

\section{$\mathrm{RCPi}=\mathrm{iC} /(\mathrm{Ai}-\mathrm{iB})$}

A RCP pode indicar se os fatores domésticos estão recebendo o seu retorno normal $(\mathrm{RCP}=1)$, acima do retorno normal $(\mathrm{RCP}<1)$ ou abaixo do retorno normal $(\mathrm{RCP}>1)$.

b) Custo dos Recursos Domésticos (CRD): O CRD é uma medida de vantagem comparativa mais criteriosa que a lucratividade social. Indica o comportamento da lucratividade social, ou seja, quanto se despende de recursos domésticos em valores sociais para gerar uma unidade de divisas por meio da exportação (equação 8).

\section{CRDi=iGi/i(Ei-iF)}

Minimizar o CRD é o equivalente a maximizar os lucros sociais. O CRD $<1$ significa que se estaria utilizando menos de um dólar de recursos domésticos para gerar um dólar de divisas e vice-versa. Indica, também, eficiência da produção.

c) Coeficiente de Proteção Nominal (CPN): O CPN indica o impacto da política que provoca divergências entre preços privados e sociais. É a razão entre os preços privados e sociais (equação 9) (FERREIRA NETO, 2005).

$\mathrm{CPNi}=\mathrm{iA} / \mathrm{E}$
Tem-se o CPN sobre produtos comercializáveis (CPNp) e sobre os insumos comercializáveis (CNPi) (equações 10 e 11, respectivamente).

$$
\begin{aligned}
& \mathrm{CPNp}=\mathrm{A} / \mathrm{E} \\
& \mathrm{CPNi}=\mathrm{B} / \mathrm{F}
\end{aligned}
$$

Um CPNp > 1 mostra que existe transferência de renda da sociedade para os produtores e vice-versa, e um CPNi > 1 indica transferência de renda negativa aos produtores, pois os custos dos insumos comercializáveis são aumentados pela política e viceversa (ROSADO et al., 2006).

d) Coeficiente de Proteção Efetiva (CPE): O CPE é importante, pois permite indicar a extensão dos incentivos ou do desestímulo que os sistemas produtivos recebem das políticas de preços de produtos e de insumos comercializáveis. Se CPE $>1$, os lucros privados são maiores que do que eles seriam sem as políticas dos produtos e insumos comercializáveis conjuntamente, ou seja, o efeito líquido das políticas contribui para aumento do lucro privado e vice-versa. O CPE é obtido do seguinte modo (equação 12) (ROSADO et al., 2006):

$$
\mathrm{CPE}=(\mathrm{A}-\mathrm{B}) /(\mathrm{E}-\mathrm{F})
$$

e) Coeficiente de Lucratividade (CL): O CL mede o efeito dos incentivos de todas as políticas. É obtido conforme a equação 13 (FERREIRA NETO, 2005).

$$
\mathrm{CL}=(\mathrm{A}-\mathrm{B}-\mathrm{C}) /(\mathrm{E}-\mathrm{F}-\mathrm{G})=\mathrm{D} / \mathrm{H}
$$

f) Taxa de Subsídios aos Produtores (TSP): A TSP mostra a proporção de renda, em valores sociais, que seria requerida para manter a eficiência econômica se um subsídio ou imposto fosse substituído por um conjunto de políticas, de outra natureza. É uma medida da transferência líquida de políticas (L) como uma proporção das receitas sociais totais (E) (equação 14). Quanto menor a TSP, menos distorcido o sistema (NEVES, 2002).

$$
\mathrm{TSP}=\mathrm{iL} / \mathrm{Ei}=\mathrm{i}(\mathrm{Di}-\mathrm{iH}) / \mathrm{E}
$$

\subsection{Sistemas de produção da madeira de eucalipto}

Foram analisados quatro sistemas de produção - I, II, III e IV.

O sistema I representa um nível de produtividade mais baixa, com $180 \mathrm{~m}^{3}$ por hectare no sétimo ano. $\mathrm{O}$ plantio é feito em áreas motomecanizáveis, ou seja, em áreas planas com espaçamento de $3 \mathrm{~m}$ x $3 \mathrm{~m}$ e com 1.111 plantas por hectare. Além disso, utiliza-se baixa

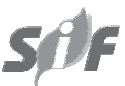

Revista Árvore, Viçosa-MG, v.34, n.5, p.917-928, 2010 
a média tecnologia. Os custos envolvidos nesse sistema de produção relaciona-se a fertilizantes, defensivos, mudas, limpeza da área, marcação de covas, coveamento, calagem e adubação, plantio e replantio, combate a formiga, capina manual, roçagem manual, construção e manutenção de aceiros, corte e toragem, baldeio, carregamento e transporte da colheita.

O sistema II é semelhante ao anterior: possui a mesma produtividade, espaçamento e plantas por hectare. Também é caracterizado por baixa a média tecnologia. Porém, o plantio é feito em áreas não motomecanizáveis, ou seja, em áreas mais acidentadas. Os custos envolvidos nesse sistema de produção são os mesmos presentes no ssitema I, porém com uso mais intensivo de mão de obra.

O sistema III apresenta um nível de produtividade mais alto, com $245 \mathrm{~m}^{3}$ por hectare no sétimo ano. Nesse sistema, o plantio é feito em áreas motomecanizáveis com alta tecnologia, também com espaçamento de 3 m x 3 m e 1.111 plantas por hectare. Os custos envolvidos nesse sistema de produção inclui os mesmos do sistema II, com excessão do custo das roçadas e capinas manuais, mais aplicação de herbicida pré-plantio, aplicação de gel, aplicação de herbicidas aos 90 dias e aplicação de herbicidas aos 10 dias.
O sistema IV refere-se ao plantio em áreas não motomecanizáveis com alta tecnologia. Essa é a única diferença desse sistema com o citado anteriormente.

\subsection{Fonte de dados}

Os dados utilizados neste trabalho referem-se ao ano de 2007 e foram obtidos no Centro de Estudos Avançados em Economia Aplicada (CEPEA, 2008), no estudo de Baier e Pérramon (2008), na Food and Agriculture Organization (FAO, 2008), no AGRIANUAL (2008) e no Centro de Desenvolvimento do Agronegócio (CEDAGRO, 2008).

Para o cálculo dos custos, adotou-se um horizonte temporal de 7 anos. Os preços dos insumos no exterior referem-se ao preço no Chile e de países de tradição florestal como Canadá, Finlândia e Suécia, e foram internalizados no Brasil, multiplicando-os por uma taxa de câmbio de 2,00, valor esse observado para o ano de 2007. Na Tabela 2, apresentam-se os custos dos insumos não comercializáveis e dos insumos comercializáveis utilizados para cálculo neste trabalho, no Brasil e no exterior. Ressalta-se que o preço do eucalipto considerado para o Brasil e o exterior foram de $\mathrm{R} \$ 55 \mathrm{~m}^{3}$ e $\mathrm{R} \$ 70 \mathrm{~m}^{3}$, respectivamente.

Tabela 2 - Custos dos insumos não comercializáveis e dos insumos comercializáveis.

Table 2 - No-marketable inputs and marketable inputs costs.

\begin{tabular}{|c|c|c|c|c|c|c|c|c|}
\hline \multirow[t]{2}{*}{ Itens } & \multicolumn{4}{|c|}{ Preço Privado $\left(\mathrm{R} \$ / \mathrm{m}^{3}\right)$} & \multicolumn{4}{|c|}{ Preço Social $\left(\mathrm{R} \$ / \mathrm{m}^{3}\right)$} \\
\hline & SistemaI & SistemaII & SistemaIII & SistemaIV & SistemaI & SistemaII & SistemaIII & SistemaIV \\
\hline CUSTO TOTAL & 34,41 & 34,41 & 38,11 & 34,10 & 33,86 & 34,61 & 32,26 & 32,50 \\
\hline a) Não Comercializáveis & 29,50 & 29,50 & 33,19 & 27,96 & 29,09 & 29,85 & 27,75 & 28,44 \\
\hline Preparo do solo & 5,00 & 5,00 & 5,78 & 4,55 & 2,89 & 2,89 & 2,12 & 4,09 \\
\hline Plantio e replantio & 0,78 & 0,78 & 0,89 & 0,65 & 1,78 & 1,78 & 1,31 & 1,31 \\
\hline Combate a formiga & 0,28 & 0,28 & 1,53 & 0,82 & 0,89 & 0,89 & 0,65 & 0,65 \\
\hline Capina Manual & 1,11 & 1,11 & 1,22 & 0,33 & 0,89 & 0,89 & 0,65 & 0,65 \\
\hline Roçagem Manual & 1,11 & 1,11 & 1,33 & - & 0,89 & 0,89 & 1,32 & - \\
\hline Corte e toragem & 1,67 & 1,67 & 2,00 & 2,04 & 0,89 & 0,89 & 0,65 & 0,65 \\
\hline Baldeio & 2,11 & 2,11 & 2,56 & 1,88 & 1,79 & 2,17 & 1,60 & 1,94 \\
\hline Carregamento & 2,44 & 2,44 & 2,89 & 2,12 & 2,08 & 2,46 & 1,80 & 2,15 \\
\hline Transporte & 15,00 & 15,00 & 15,00 & 15,00 & 17,00 & 17,00 & 17,00 & 17,00 \\
\hline Aplicação de gel & - & - & - & 0,56 & - & - & 0,65 & 0,65 \\
\hline b) Comercializável & 4,91 & 4,91 & 4,91 & 6,14 & 4,76 & 4,76 & 4,51 & 4,06 \\
\hline Mudas & 3,33 & 3,33 & 3,33 & 2,45 & 0,67 & 0,67 & 0,49 & 0,63 \\
\hline Calcário & 0,16 & 0,16 & 0,16 & 0,55 & 0,67 & 0,67 & 0,49 & 0,49 \\
\hline Nitrogênio & 0,31 & 0,31 & 0,31 & 0,69 & 0,67 & 0,67 & 0,49 & 0,49 \\
\hline Fósforo & 0,38 & 0,38 & 0,38 & 0,56 & 0,67 & 0,67 & 0,49 & 0,49 \\
\hline Potássio & 0,14 & 0,14 & 0,14 & 0,31 & 0,67 & 0,67 & 0,49 & 0,49 \\
\hline Formicida & 0,47 & 0,47 & 0,47 & 0,31 & 0,67 & 0,67 & 0,49 & 0,49 \\
\hline Cupinicida & 0,11 & 0,11 & 0,11 & 0,08 & 0,76 & 0,76 & 0,49 & 0,49 \\
\hline Fosfato Natural & - & - & - & 1,31 & - & - & 0,49 & 0,49 \\
\hline Herbicida & - & - & - & 0,40 & - & - & 0,59 & - \\
\hline
\end{tabular}

Fonte: AGRIANUAL, 2008; CEDAGRO, 2008; BAIER e PÉRRAMON, 2008; FAO, 2008.

Source: AGRIANUAL, 2008; CEDAGRO, 2008; BAIER and PÉRRAMON, 2008; FAO, 2008.

Revista Árvore, Viçosa-MG, v.34, n.5, p.917-928, 2010 


\section{RESULTADOS E DISCUSSÃO}

\subsection{Lucratividades privadas e sociais}

Na tabela 3 estão os resultados da MAP para a cadeia produtiva da madeira de eucalipto no Brasil.

Os resultados evidenciam que a lucratividade privada da produção e comercialização do eucalipto para o mercado interno no setor produtivo foi positiva, com valores de $\mathrm{R} \$ 20,59, \mathrm{R} \$ 16,89, \mathrm{R} \$ 20,90$ e R \$20,34 por $\mathrm{m}^{3}$, nos sistemas I, II, III e IV respectivamente (Tabela 3). Em outras palavras, os sistemas de produção sob análise são competitivos na produção da madeira de eucalipto.

As lucratividades sociais nos sistemas I, II, III e IV, foram da ordem de R\$36,14, R\$35,39, R\$37,74 e $\mathrm{R} \$ 37,50 \mathrm{~m}^{3}$, respectivamente (Tabela 3). Ressalta-se, ainda, que a lucratividade social positiva, nos quatro sistemas, indica que há eficiencia econômica na produção da madeira de eucalipto no Brasil. Além disso, esses resultados demonstram que a produção é eficiente na alocação de recursos nacionais e na geração de divisas. Apesar de a madeira de eucalipto não ser exportada, a celulose, seu prinicipal produto final, o é em grande quantidade, sendo grande atrativo de divisas, uma vez que o Brasil é o segundo exportador mundial de celulose de todos os tipos e o maior exportador mundial de celulose de fibra curta derivada do eucalipto, conforme FAO (2008) e Bracelpa (2007).

Em termos comparativos, a produção da madeira de eucalipto no sistema III apresentou maior lucratividade privada e social, mostrando a eficiência e a maior competitividade desse sistema de produção, onde se encontram os de maior produtividade do eucalipto com a produção em áreas planas.

Pode-se dizer, também, que os lucros privados foram bem inferiores aos sociais em todos os sitemas tecnológicos. Isso pode ser devido à ineficiência de políticas públicas implementadas, ou seja, à ineficiência das políticas públicas na tributação, na taxa de câmbio, nos encargos sociais e nas políticas comerciais.

\subsection{Transferências financeiras associadas a preço do produto}

Os resultados da MAP, para o setor produtivo da madeira de eucalipto, mostraram que os preços privados são menores que os preços internacionais, o que evidencia uma transferência negativa de $\mathrm{R} \$ 15,00$ por $\mathrm{m}^{3}$. Assim, pode-se inferir que os produtores brasileiros foram penalizados por políticas distorcivas como política de juros, política cambial, tributária e comercial, dado

Tabela 3 - Matriz de análise política da madeira de eucalipto, Brasil, 2007.

Table 3 - Policy Analysis Matrix for eucalyptus wood, Brazil, 2007.

\begin{tabular}{|c|c|c|c|c|}
\hline \multirow[t]{2}{*}{ Sistemas Tecnológicos } & \multirow[t]{2}{*}{ Receita } & \multicolumn{2}{|c|}{ Custos de Comercialização } & \multirow[t]{2}{*}{ Lucro } \\
\hline & & $\begin{array}{c}\text { Insumos } \\
\text { Comercializáveis } \\
\end{array}$ & $\begin{array}{c}\text { Fatores } \\
\text { Domésticos }\end{array}$ & \\
\hline \multicolumn{5}{|l|}{ Sistema I } \\
\hline Preços Privados & 55,00 & 4,91 & 29,50 & 20,59 \\
\hline Valorações Sociais & 70,00 & 4,76 & 29,09 & 36,14 \\
\hline Efeitos de Divergências & $-15,00$ & 0,15 & 0,41 & $-15,56$ \\
\hline \multicolumn{5}{|l|}{ Sistema II } \\
\hline Preços Privados & 55,00 & 4,91 & 33,19 & 16,89 \\
\hline Valorações Sociais & 70,00 & 4,76 & 29,85 & 35,39 \\
\hline Efeitos de Divergências & $-15,00$ & 0,15 & 3,34 & $-18,49$ \\
\hline \multicolumn{5}{|l|}{ Sistema III } \\
\hline Preços Privados & 55,00 & 6,14 & 27,96 & 20,90 \\
\hline Valorações Sociais & 70,00 & 4,51 & 27,75 & 37,74 \\
\hline Efeitos de Divergências & $-15,00$ & 1,62 & 0,21 & $-16,84$ \\
\hline \multicolumn{5}{|l|}{ Sistema IV } \\
\hline Preços Privados & 55,00 & 5,58 & 29,08 & 20,34 \\
\hline Valorações Sociais & 70,00 & 4,06 & 28,44 & 37,50 \\
\hline Efeitos de Divergências & $-15,00$ & 1,53 & 0,64 & $-17,17$ \\
\hline
\end{tabular}

Fonte: Dados da pesquisa.

Source: Research data. 
que essa atividade recebeu menos do que receberia, se essas políticas não tivessem sido implantadas. Em outras palavras, os produtores poderiam ter alcançado níveis maiores de lucratividade, caso não tivessem sido penalizados por políticas distorcivas. Mas, mesmo assim, verifica-se que os sistemas são lucrativos (Tabela 3).

Ressalta-se ainda que, como os preços internos estão menores que os internacionais, ocorreu transferência de renda dos produtores para a sociedade.

\subsection{Transferências financeiras associadas a preços dos insumos}

Os valores encontrados para as transferências associadas aos custos dos insumos comercializáveis foram de $\mathrm{R} \$ 0,15, \mathrm{R} \$ 0,15$, R \$1,62 e R \$1,53 por $\mathrm{m}^{3}$, nos sistemas I, II, III e IV, respectivamente (Tabela 3).

Como se trata de insumos comercializáveis, pode-se dizer que os efeitos de divergências entre os valores privados e sociais são atribuídos às políticas distorcivas e não às imperfeições do mercado. Essas políticas distorcivas fazem que exista divergência entre os preços nos mercados nacional e internacional. O impacto do Imposto sobre Circulação de Mercadorias e Serviços (ICMS) é um exemplo desse tipo de política distorciva. Acredita-se que se o governo não tivesse taxado o preço dos insumos comercializáveis, os custos nos sistemas de produção da madeira de eucalipto teriam sido menores, estimulando o desenvolvimento da atividade e contribuindo para o aumento da renda do produtor. A eliminação ou a redução de alíquotas sobre os insumos favoreceriam a competitividade da madeira de eucalipto e, consequentemente, da celulose no mercado internacional.

Quanto às tranferências associadas aos fatores domésticos, nos sistemas I, II, III e IV estas foram da ordem de $\mathrm{R} \$ 0,41, \mathrm{R} \$ 3,34, \mathrm{R} \$ 0,21$ e $\mathrm{R} \$ 0,64$ por $\mathrm{m}^{3}$, respectivamente. Esses valores positivos significam custos privados maiores que os custos sociais dos fatores domésticos. Em outras palavras, representa transferência negativa para o setor produtivo, uma vez que contribuiu para a redução do lucro privado.

Os sistemas I e III apresentaram os menores valores de transferências, o que indica menor divergência entre custos privados e sociais dos fatores domésticos e mostra maior eficiência no uso dos fatores domésticos nesses sistemas.

Revista Árvore, Viçosa-MG, v.34, n.5, p.917-928, 2010

\subsection{Transferências financeiras associadas à lucratividade (transferências líquidas)}

A transferência é o resultado principal da MAP, pois esse valor mostra a extensão de ineficiência de um sistema agrícola de produção (MOSS, 2006).

Nos quatro sistemas analisados, as transferências líquidas foram negativas. São elas de R \$15,56, R \$18,49, $\mathrm{R} \$ 16,84$ e $\mathrm{R} \$ 17,17$ por $\mathrm{m}^{3}$, nos sistemas I, II, III e IV, respectivamente. Esses resultados indicam que os produtores de madeira de eucalipto tiveram seus lucros reduzidos, o que pode estar relacionado com taxações impostas à produção e à comercialização da madeira de eucalipto, apesar de serem sistemas que operam com lucro.

Verificou-se que a produção em áreas não motomecanizáveis com baixa a média tecnologia (sistema II) apresentou transferências maiores, indicando que os produtores desse sistema de produção foram mais penalizados por políticas públicas distorcivas. Já a produção em áreas motomecanizáveis apresentou a menor transferência líquida. Isso pode estar relacionado com os custos sociais mais elevados, o que resultou em menor lucro social, daí a menor transferência e não por ser o sistema menos afetado por políticas distorcivas.

A lucratividade privada é um indicador importante para que o produtor se sinta estimulado a produzir. Para que esse fato ocorra é necessário que o governo proporcione melhores alternativas de políticas, como as reduções nas taxações incidentes tanto no produto quanto nos insumos usados na produção (MOSS, 2006), o que teria como consequência o aumento da lucratividade e a posterior competitividade da madeira de eucalipto.

\subsection{Indicadores de competitividade privados e sociais}

Na tabela 4 podem ser observados os valores privados e sociais gerados pela MAP.

Verificou-se que a RCP da produção da madeira de eucalipto no sistema III apresenta maior competitividade aos sistemas I, II e IV. Mas, como a RCP é menor que um em todos os sistemas analisados, considera-se que esses são lucrativos e remunerados acima do seu retorno normal. Assim, no sistema III apenas 57\% do valor adicionado, ou seja, da diferença entre receita e custo dos insumos comercializáveis, a valores privados é requerido para pagar os fatores domésticos e produzir $1 \mathrm{~m}^{3}$ a mais de madeira de eucalipto, 
Tabela 4 - Indicadores de competitividade privados e sociais gerados pela MAP. Table 4 - Private and social competitiveness indicators generated by the PAM.

\begin{tabular}{lccc}
\hline Indicadores & Sistema I & Sistema II & Sistema III \\
\hline RCP & 0,59 & 0,66 & 0,57 \\
CRD & 0,45 & 0,46 & 0,42 \\
CPNp & 0,79 & 0,79 & 0,79 \\
CPNi & 1,03 & 1,03 & 1,36 \\
CPE & 0,77 & 0,77 & 0,73 \\
CL & 0,57 & 0,48 & 0,79 \\
TSP & $-0,22$ & $-0,26$ & 0,55 \\
\hline
\end{tabular}

Fonte: Dados da pesquisa.

Source: Research data.

por hectare, para consumo doméstico. Raciocínio análogo pode ser feito para os demais sitemas produtivos. Apenas 59\%, 66\% e 59\% do valor adicionado a valores privados é requerido para pagar os fatores domésticos e produzir $1 \mathrm{~m}^{3}$ a mais de eucalipto, por hectare, para consumo doméstico nos sistemas I, II e IV (Tabela 4). Desse modo, esses setores produtivos podem manter os níveis de utilização dos fatores domésticos e, assim, progredir nessa atividade.

Os CRDs inferiores a 1 nos diferentes sistemas produtivos indicam eficiência de produção e competitividade, pois se gastaram apenas $\mathrm{R} \$ 0,45, \mathrm{R} \$ 0,46$, $\mathrm{R} \$ 0,42$ e $\mathrm{R} \$ 0,43$ em recursos domésticos para gerar $\mathrm{R} \$ 1,00$ de divisas, por meio de exportação nos sistemas I, II, III e IV, respectivamente. Isso mostra a vantagem competitiva do Brasil nas exportações de celulose, principal produto derivado do eucalipto. Então, podese dizer que a expansão dessa atividade representa ganhos líquidos para o Brasil, em termos de alocação de recursos. Além disso, os sistemas produtivos com maior nível tecnológico na produção da madeira de eucalipto apresentaram maior eficiência econômica na alocação de recursos (Tabela 4).

Os CPNp foram da ordem de 0,79 em todos os sistemas de produção analisados, como era esperado. Como os valores encontrados foram menores que a unidade, há desproteção à atividade, uma vez que o produtor de madeira de eucalipto recebe um preço interno menor que o do internacional. Além disso, esses resultados indicam que existem taxações implícitas sobre os sistemas de produção do eucalipto resultantes das medidas de políticas, uma vez que seus preços encontram abaixo dos internacionais, o que levou os produtores a receberem $21 \%$ a menos do que os preços praticados no mercado internacional (Tabela 4).
Como os resultados encontrados para o CNPj foram maiores que 1 em todos os sistemas analisados, observou-se que há transferências negativas de 3\%, 3\%, 36\% e 38\% nos sistemas I, II, III e IV, respectivamente, pois os custos dos insumos comercializáveis são aumentados pela intervenção política. Os valores do CNPi mostram, ainda, que os produtores de eucalipto que utilizam maior nível tecnológico receberam taxação mais alta devido a essas políticas distorcivas praticadas no setor (Tabela 4).

O CPE dos sistemas I, II, III e IV foram, respectivamente, de 0,$77 ; 0,77 ; 0,75$; e 0,75 , ou seja, os valores foram menores que 1 , indicando elevada desproteção ou taxação no setor produtivo da madeira de eucalipto no país. Isso demonstra que o setor foi penalizado por políticas públicas distorcivas (Tabela 4).

Os resultados dos CPEs nos sistemas III e IV, em comparação com os mesmos coeficientes obtidos nos sistemas I e II, segundo Alves (2002), corroboram a constatação de que tecnologia mais avançada proporciona redução dos efeitos negativos de políticas, seja com a redução dos custos, seja com a possibilidade de obter melhores preços para o produto.

Os CL encontrados foram menores que 1 e variaram de 0,48 a 0,57, o que significa que a produção da madeira de eucalipto foi liquidamente taxada e o lucro privado reduziu. Significa, também, desproteção total da produção de eucalipto no Brasil (Tabela 4).

A TSP indica que os quatro sistemas produtivos analisados sofreram alguma taxação, por apresentarem valores negativos. Os sistemas I, II, III e IV foram taxados ou tiveram suas receitas reduzidas, respectivamente, em 22\%, 26\%, 24\% e 24\% (Tabela 4).

Revista Árvore, Viçosa-MG, v.34, n.5, p.917-928, 2010 


\section{CONCLUSÃO}

Concluiu-se que a lucratividade privada e social da produção e comercialização da madeira de eucalipto foi positiva em todos os sistemas de produção analisados e maior nas áreas motomecanizáveis; a produção em áreas motomecanizáveis apresentou-se mais competitiva e menos exposta aos efeitos negativos das políticas públicas; e a cultura do eucalipto no Brasil vem sofrendo com políticas públicas distorcivas como impostos e taxas elevados, mas, mesmo assim, é lucrativa e competitiva. Do contrário, os produtores brasileiros poderiam ter alcançado níveis mais altos de lucratividade e competitiva.

\section{AGRADECIMENTOS}

Ao Conselho Nacional de Desenvolvimento Científico e Tecnológico (CNPq), pelo financiamento; e à Universidade Federal de Viçosa, pelo fornecimento da estrutura e pessoal.

\section{REFERÊNCIAS}

Agrianual. Anuário estatístico da agricultura brasileira. São Paulo: FNP Consultoria e Comércio, 2008.

AHMAD, S.; MARTINI, R. P. Agricultural Policy Analysis in Pakistan: Illustrations in the use of the Policy Analysis Matrix. Working Paper, 2000. Disponível em:< http://ravi.lums.edu.pk/ cmer/upload/agricultural\%20policy\%20analysis. pdf> Acesso em: 08/07/2008.

ALVES, J. M. Competitividade e tendência da produção de manga para exportação do nordeste do Brasil. Piracicaba, SP: ESALQ/USP, 2002. 163f. Tese (Doutorado em Ciências: Área de Concentração Economia Aplicada) - Escola Superior de Agricultura “Luiz de Queiroz”, Piracicaba, 2002.

ASSOCIAÇÃO BRASILEIRA DE CELULOSE E PAPEL - BRACELPA. Setor de Celulose e Papel. 2007. Disponível em: <http:// www.bracelpa.org.br/bra/eveventos_bracelpa/ press_release.pdf $>$. Acesso em: 03/04/2008.

ASSOCIAÇÃO BRASILEIRA DOS PRODUTORES DE FLORESTAS PLANTADAS - ABRAF. Anuário Estatístico da ABRAF 2009. Disponível em: <http://www.abraflor.org.br/ estatisticas.asp>. Acesso em: 02/06/2009.
ASSOCIAÇÃO MINEIRA DE SILVICULTURAAMS. Eucalipto. Disponível em: <http:// www.silviminas.com.br>. Acesso em: 20/03/2008.

\section{ASSOCIAÇÃO MINEIRA DE SILVICULTURA - AMS Por dentro do Eucalipto: \\ Aspectos sociais, ambientais e econômicos do seu cultivo. 2009.Disponível em: <http:// www.silviminas.com.br>. Acesso em: 02/06/2009.}

BAIER, J. C. V.; PÉRRAMON, J. A. C. Análisis económico de opciones productivas para plantaciones de eucalyptus nitens en el sur de Chile. 2006 Disponível em: <http:// www.chilenoticias.cl/revista_cifor/textos/ e_nitens.pdf $>$. Acesso em: 20/05/2008.

\section{CENTRO DE DESENVOLVIMENTO DO \\ AGRONEGÓCIO - CEDAGRO. Coeficientes \\ técnicos. Disponível em: <http:// \\ www.cedagro.org.br> Acesso em: 14/06/2008.}

\section{CENTRO DE ESTUDOS AVANÇADOS EM \\ ECONOMIAAPLICADA - CEPEA.}

Informativo CEPEA - Setor Florestal. Disponível em: <http://www.cepea.esalq.usp.br>. Acesso em: 11/02/2008.

COELHO, M. R. F.; BERGER, R. Competitividade das exportações brasileiras de móveis no mercado internacional: uma análise segundo a visão desempenho. Revista FAE, v.7, n.1, p.51-65, 2004.

ENDOM, M. A. Economic analysis of large scale logging. Working Paper, n.3. 1999. Disponível em: <http:// www.worldagroforestry.org/sea/Publications/ files/workingpaper/WP0021-04.PDF>. Acesso em: 07/07/2008.

FERREIRA NETO, J. Competitividade da produção de cana-de-açúcar no Brasil. 2005. 87f. Dissertação (Mestrado em Economia Aplicada) - Universidade Federal de Viçosa, Viçosa, MG, 2005.

FOOD AND AGRICULTURE ORGANIZATION FAO. Disponível em: <http//:www.fao.org $>$. Acesso em: 23/04/2008. 
GOMES, M. T. M. Potencialidades de inserção do carvão vegetal em bolsa de mercadorias. 2006. 71f. Dissertação (Mestrado em Ciência Florestal) - Universidade Federal de Viçosa, Viçosa, MG, 2006.

HADI, P. U.; BUDHI, G. S. Analysis of the economic efficiency and comparative advantage of the sumatran smallholder rubber using “PAM" method. Working Paper, n., 4, 1997. Disponível em: <http://www.worldagroforestrycenter.org/sea/ Publications/files/workingpaper/WP0022-04.PDF>. Acesso em 22/08/2008.

HAGUENAUER, L. Competitividade: conceitos e medidas: uma resenha da bibliográfica recente com ênfase no caso brasileiro. Rio de Janeiro: Universidade Federal do Rio de Janeiro - Instituto de Economia Industrial, 1989. 20p. (Texto para Discussão, 211)

IE/UNICAMP - IEI/UFRJ - FDC - FUNCEX. Estudo da competitividade da indústria brasileira. Sistema de indicadores da competitividade. Campinas: 1993. 202p. (Nota Técnica).

MARYANI, R.; IRAWANTI, S. Economics analysis of land use system for large scale plantations of oil palm and industrial timber estate. 1997.(Working Paper, 2). Disponível em: http:// www.worldagroforestry.org/Sea/Publications/ files/workingpaper/WP002004.pdf>. Acesso em: 07/07/2008.

MARRA, R. et al. Cadeia produtiva do café em Minas Gerais. In: VIEIRA, R. C. M. T. et al. Cadeias produtivas no Brasil: análise da competitividade. Brasília: Embrapa Comunicação para Transferência Tecnológica, Secretaria de Administração Estratégica, 2001. p.139-154.

MARTINS, P. C. Efeitos de políticas públicas sobre a cadeia produtiva do leite em pó. In: VIEIRA, R. C. M. T. et al. Cadeias produtivas no Brasil: análise da competitividade. Brasília: Embrapa Comunicação para Transferência Tecnológica. Secretaria de Administração Estratégica, 2001. p.241-272.

MEDEIROS, V. X.; FONTES, R. M. O. Competitividade das exportações brasileiras de celulose no mercado internacional. Revista de Economia e Sociologia Rural, v.32, n.2, p.105-121, 1994.
MOHANTY, S.; FANG, C.; CHAUDHARY, J. Assessing the competitiveness of indian cotton production: a policy analysis matrix approach. Working Paper, 2002. Disponível em:< http://www.card.iastate.edu/publications/DBS/ PDFFiles/02wp301.pdf>. Acesso em: 08/07/2008.

MONKE, A. E.; PEARSON, S. R. The policy analysis matrix for agricultural development. New York: Cornell University Press, 1989. 278p.

MONTEBello, A. E. S. Análise da evolução da indústria brasileira de celulose no período de 1980 a 2005. 2006. 115f. Dissertação (Mestrado em Ciências - Área de Concentração: Economia Aplicada) - Escola Superior de Agricultura Luiz de Queiroz, Piracicaba, 2006.

MOSS, S. R. Competitividade da produção do café arábica em Minas Gerais e São Paulo. 2006. 90f. Dissertação (Mestrado em Economia Aplicada) - Universidade Federal de Viçosa, Viçosa, MG, 2006.

NELSON, A. W. Applications of the Policy Analysis Matrix (PAM). Working Paper, 1991. Disponível em:<http://www.ifpri.org/ training/material/miscellaneous/Foodpolicycom AppendixF_policymemoranda.pdf. Acesso em: 08/07/2008.

NELSON, C. G.; PANGGABEAN, M. “The costs of indonesian sugar policy: A policy analysis matrix approach.” American Journal of Agricultural Economics, v.73, p.703-12, 1991.

NOCE, R. et al. Desempenho do Brasil na Produção de Madeira Serrada. Revista Arvore, v.27, n.5, p.695-700, 2003.

NOCE, R. et al. Preço relativo e competitividade no mercado internacional de, compensado. Revista Cerne, v.13, n.1, p.51-56, 2007.

NOCE, R. et al. Competitividade do Brasil no mercado internacional de aglomerado. Revista Arvore, v.32, n.1, p.113-118, 2008.

PIZZOL, S. J. S.; BACHA, C. J. C. Evolução, estrutura e desafios da indústria de celulose no Brasil. Preços Agrícolas, v.12, n.137, p.3-13, 1998.

Revista Árvore, Viçosa-MG, v.34, n.5, p.917-928, 2010 
ROSADO, P. L. Competitividade e expansão da avicultura e suinocultura no contexto do MERCOSUL. 1997. $105 f$.

Dissertação (Mestrado em Economia Rural) -

Universidade Federal de Viçosa, Viçosa, MG, 1997.

ROSADO, P. L.; TOSTO, S. G.; GOMES, M. F. M.

Competitividade e expansão da produção de

borracha natural brasileira, no contexto de

liberalização dos mercados. In: ALVARENGA, A. P. et al. Seringueira: aspectos econômicos

sociais e perspectivas para o seu fortalecimento.

Viçosa, MG: 2006. p.103-128.
SOARES, N. S. Potencial de implantação de um contrato futuro da madeira de reflorestamento. 2006. 121f. Dissertação (Mestrado em Ciência Florestal) - Universidade Federal de Viçosa, Viçosa, MG, 2006.

VALVERDE, S. R.; SOARES, N. S.; SILVA, M. L.

Desempenho das exportações brasileiras de celulose. Revista Árvore, v.30, n.6, p.1017-1023, 2006.

VIEIRA, R. C. M. T. et al. Cadeias produtivas no Brasil - análise da competitividade. Revista de Política Agrícola, v.10, n.4, p.7-15, 2001. 